Reprod. Nutr. Dévelop., 1987, 27 (1 B), 251-252.

\title{
Composition en oses neutres des bactéries attachées aux résidus de digestion : incidence sur l'évaluation de la digestibilité dans le rumen
}

\author{
J. L. BARRY, F. LAMY, Christine HOEBLER
}

Laboratoire de Technologie des Aliments des Animaux, I.N.R.A., 44072 Nantes Cedex, France.

Summary. Bacteria linked to 48-hour rumen fermentation residues represented 2.3 to $4.4 \%$ of residues dry matter and contained 5.7 to $11.6 \%$ neutral sugars : they interfered only to a limited extent, but for rhamnose with neutral sugars of cell wall polysaccharides in fermentation residues.

Dans le résidu de digestion des aliments dans le rumen, les oses des composés pariétaux, dosés par chromatographie en phase gazeuse, incluent ceux des bactéries attachées; il en résulte une sous-évaluation des résultats de la mesure de la digestibilité d'aliments en milieu de rumen. Le présent travail a pour objet d'évaluer l'importance de cette source possible d'erreur.

Matériel et méthodes. Quatre matières premières, riches en constituants pariétaux (paille de blé, téguments de soja, pulpe de betterave déshydratée, tourteau de palmiste), ont été fermentées in vitro pendant $48 \mathrm{~h}$ en Rusitec (Czerkawski et Breckenridge, 1977). Un foin de pré a été digéré in vitro en sacs de nylon pendant la même durée. Les bactéries des résidus de cette fermentation ont été extraites et purifiées selon la technique de Merry et McAllan (1983). La composition en oses neutres des parois des aliments et des résidus de digestion d'une part et d'autre part des bactéries a été déterminée par chromatographie en phase gazeuse après hydrolyse sulfurique, selon une technique décrite par ailleurs (Barry et al., 1987). Les teneurs en cellulose ont été estimées à partir du glucose, celles en hémicelluloses à partir de la somme des autres oses.

Résultats et discussion. Les bactéries constituent $4,4 \%$ de la matière sèche des résidus de foin, donnée en accord avec les estimations de Durand (communication personnelle). Dans les résidus d'incubation in vitro des autres substrats, elles n'en représentent que $2,3 \%$ pour la pulpe et la paille et $2,7 \%$ pour le tégument de soja et le tourteau de palmiste.

TABL. 1. - Composition centésimale en oses neutres des bactéries attachées aux résidus de digestion (\% M.S.).

\begin{tabular}{lcccccc}
\multicolumn{1}{c}{ Substrat } & Foin & Paille & $\begin{array}{c}\text { Téguments } \\
\text { de soja }\end{array}$ & $\begin{array}{c}\text { Pulpe } \\
\text { de betterave }\end{array}$ & $\begin{array}{c}\text { Tourteau } \\
\text { de palmiste }\end{array}$ & Moyenne \\
\hline Oses : & & & & & & \\
Rhamnose ... & 0,70 & 0,65 & 0,88 & 0,88 & 0,24 & 0,62 \\
Arabinose ... & 0,29 & 0,73 & 0,45 & 0,35 & 0,15 & 0,39 \\
Xylose ...... & 0,34 & $1,82^{*}$ & 0,17 & 0,13 & 0,21 & 0,21 \\
Mannose .... & 0,38 & 0,69 & 0,48 & 0,51 & $1,80^{*}$ & 0,51 \\
Galactose ... & 0,73 & 1,10 & 0,64 & 0,85 & 1,40 & 0,94 \\
Glucose ..... & 3,30 & 5,29 & 5,14 & $\mathbf{8 , 9 1}$ & 6,35 & 5,80 \\
\hline
\end{tabular}

\footnotetext{
* Données exclues du calcul de la moyenne. Voir texte.
} 
La totalité des oses représente de 5,7 à $11,6 \%$ de la matière sèche des bactéries (tabl. 1). Le glucose en est l'ose principal. Le galactose, le rhamnose et le mannose sont également présents, à des taux généralement inférieurs à $1 \%$. Les teneurs élevées en xylose des bactéries " paille " et en mannose des bactéries " palmiste » sont vraisemblablement le résultat d'une pollution par ces substrats, respectivement riches en ces deux oses. Ces résultats sont en bon accord avec ceux de Jouany et Thivend (1972) et de McAllan et Smith (1974) pour le rhamnose, l'arabinose, le xylose et le mannose. En ce qui concerne le galactose et le glucose, les données de la bibliographie sont plus diverses, car les concentrations de ces oses peuvent différer significativement en fonction de la nature du substrat, de la durée d'incubation et de la disponibilité de l'azote dans le milieu de rumen.

TABL. 2. - Erreurs relatives par défaut sur les mesures de fermentescibilité des oses pariétaux dues à la présence de bactéries attachées (\% de la digestibilité).

\begin{tabular}{lcccccc}
\hline & Foin & Paille & $\begin{array}{c}\text { Téguments } \\
\text { de soja }\end{array}$ & $\begin{array}{c}\text { Pulpe } \\
\text { de betterave }\end{array}$ & $\begin{array}{c}\text { Tourteau } \\
\text { de palmiste }\end{array}$ & $\begin{array}{c}\text { Erreur } \\
\text { moyenne }\end{array}$ \\
\hline Rhamnose $\ldots$ & 5,1 & 2,6 & 1,3 & 0,5 & 5,2 & 2,9 \\
Arabinose $\ldots$ & 0,5 & 1,2 & 0,1 & 0,0 & 0,3 & 0,4 \\
Xylose $\ldots \ldots$ & 3,2 & 0,5 & 0,0 & 0,1 & 0,6 & 0,9 \\
Mannose $\ldots .$. & 1,2 & 0,8 & 0,1 & 0,4 & 0,1 & 0,5 \\
Galactose $\ldots$ & 2,3 & 4,1 & 0,3 & 0,1 & 1,2 & 1,6 \\
Glucose ..... & 1,2 & 0,5 & 0,2 & 0,4 & 2,3 & 0,9 \\
Hémicellulose & 1,7 & 0,9 & 0,2 & 0,8 & 0,2 & 0,8 \\
\hline
\end{tabular}

Estimée in vitro, la part des bactéries est pratiquement constante dans le résidu de fermentation : leur interférence sera plus forte sur la mesure de dégradabilité des aliments les moins digestibles. La teneur des bactéries en arabinose, xylose et mannose est le plus souvent beaucoup plus faible que celle des résidus correspondants : la digestibilité de ces oses sera donc peu affectée par la présence des bactéries attachées (tabl. 2). II n'en va pas de même pour le rhamnose, relativement plus concentré dans les corps bactériens. Pour le galactose et le glucose, la variabilité des teneurs dans les bactéries conditionne l'importance des corrections à apporter.

Dans les résidus de fermentation de substrats riches en constituants pariétaux, la présence d'oses neutres d'origine bactérienne n'entraîne qu'une sousévaluation mineure de la digestibilité des oses des constituants pariétaux. Pour la corriger efficacement, il convient de tenir compte de la dégradabilité du substrat et, pour certains oses, des conditions du test de fermentation.

Barry J. L., El Bouami A., Hoebler C., 1987. Reprod. Nutr. Dévelop., 27, 249-250.

Czerkawski J. W., Breckenridge G., 1977. Br. J. Nutr., 38, 371-384.

Jouany J. P., Thivend P., 1972. Ann. Biol. anim., Bioch. Biophys., 12, 679-683.

McAllan A. B., Smith R. H., 1974. Br. J. Nutr., 31, 77-88.

Merry R. J., McAllan A. B., 1983. Br. J. Nutr., 50, 701-709. 